\title{
Salinomycin co-treatment enhances tamoxifen cytotoxicity in luminal A breast tumor cells by facilitating lysosomal degradation of receptor tyrosine kinases
}

\author{
Ann-Katrin Sommer ${ }^{1,2}$, Adam Hermawan ${ }^{1}$, Frauke Martina Mickler ${ }^{3}$, Bojan Ljepoja ${ }^{1}$, \\ Pjotr Knyazev' ${ }^{2}$, Christoph Bräuchle ${ }^{3}$, Axel Ullrich ${ }^{2}$, Ernst Wagner ${ }^{1}$, Andreas Roidl ${ }^{1}$ \\ ${ }^{1}$ Pharmaceutical Biotechnology, Department of Pharmacy, Ludwig-Maximilians-Universität München, 81377 Munich, Germany \\ ${ }^{2}$ Department of Molecular Biology, Max-Planck-Institute of Biochemistry, 82152 Martinsried, Germany \\ ${ }^{3}$ Physical Chemistry, Department of Chemistry, Ludwig-Maximilians-Universität München, 81377 Munich, Germany \\ Correspondence to: Andreas Roidl, email: andreas.roidl@cup.uni-muenchen.de
}

Keywords: tamoxifen, resistance, salinomycin, endosomal trafficking, breast cancer

Received: February 3, $2016 \quad$ Accepted: June 17, $2016 \quad$ Published: July 07, 2016

\section{ABSTRACT}

Luminal A breast cancer is the most common breast cancer subtype which is usually treated with selective estrogen receptor modulators (SERMS) like tamoxifen. Nevertheless, one third of estrogen receptor positive breast cancer patients initially do not respond to endocrine therapy and about $\mathbf{4 0 \%}$ of luminal $A$ breast tumors recur in five years. In this study, we investigated an alternative treatment approach by combining tamoxifen and salinomycin in luminal A breast cancer cell lines. We have found that salinomycin induces an additional cytotoxic effect by inhibiting the ligand independent activation of ER $\alpha$. Thereby salinomycin increases the intracellular calcium level. This leads to a premature fusion of endosomes with lysosomes and thus to the degradation of Egfr family members. Since this process is essential for luminal A breast cancer cells to circumvent tamoxifen treatment, the combination of both drugs induces cytotoxicity in tamoxifen sensitive as well as resistant luminal $A$ breast cancer cell lines.

\section{INTRODUCTION}

According to the American Cancer Society breast cancer is still the second leading cause of cancer deaths among women in which luminal $\mathrm{A}$ is the most common subtype $(70 \%)[1,2]$. It is characterized by high estrogen receptor $\alpha(E R \alpha)$ as well as progesterone receptor expression levels [3, 4]. Consequently, endocrine therapy with selective estrogen receptor modulators (SERMs) like tamoxifen is the first line treatment for this type of breast cancer. This drug class acts as agonist-antagonist, as it mediates an agonistic effect on ER $\alpha$, e.g. in bone tissue and thus prevents women from osteoporosis. In parallel, it works as an antagonist on ER $\alpha$ in breast cancer tissue where it inhibits tumor growth in estrogen dependent breast cancer [5]. However, acquired or intrinsic resistance occurs in about $40 \%$ of breast cancer patients due to three major resistance mechanisms [6]: Overexpression of multidrug resistance protein 1 (MDR-1), the occurrence of so called cancer stem cells (CSCs) as well as especially in this breast cancer subtype the ligand independent activation of ER $\alpha$ via different Receptor Tyrosine Kinases (RTKs) [7-9]. For that reason, additional therapy options need to be investigated to improve patient outcome. It was previously shown that the carboxylic polyether antibiotic and ionophore salinomycin is able to overcome MDR-1 as it integrates in biological membranes [10]. Moreover, CSCs can be eradicated by salinomycin [11, 12]. Accordingly, it was recently determined that this antibiotic circumvents apoptosis-resistance by inhibition of autophagy depending on the available glucose level [13-16].

Another important effect on cancer is that salinomycin is able to reduce metastasis formation [1719] and inhibits EMT by activation of FOXO3a [20]. Salinomycin was also utilized as additive in several other combinational treatment approaches overcoming acquired drug resistance $[20,21]$.

Therefore, we investigated whether salinomycin can be utilized for a combinational approach with tamoxifen and is suitable to circumvent tamoxifen resistance. We demonstrate that salinomycin hampers 
the ligand independent activation of ER $\alpha$ which is mediated by RTKs. By increasing the intracellular calcium concentration this antibiotic facilitates Egfr and Her2 degradation via lysosomes thus blocking mitogenic signaling. Hence, salinomycin is also able to overcome tamoxifen resistance in luminal A breast cancer rendering salinomycin a promising additive anti-cancer drug.

\section{RESULTS}

\section{Combinatorial treatment with tamoxifen and salinomycin shows increased cytotoxicity in luminal A breast cancer cells}

To investigate whether salinomycin has a beneficial effect on the therapy of luminal A breast cancer, it was used as single drug or in combination with tamoxifen to treat MCF-7 and T47D luminal A breast cancer cell lines. Cell viability was examined after $72 \mathrm{~h}$ of treatment. By calculating the combination index, we observed in both cell lines a synergistic effect of the combinational treatment with tamoxifen and salinomycin [22-24] (Figure 1A). To further validate the increased cytotoxicity poly ADP ribose polymerase (PARP) cleavage, a biomarker for cell death, was analyzed by western blotting. Here, PARP1 was cleaved upon salinomycin treatment in MCF-7 and the combinatorial treatment with salinomycin and tamoxifen in both cell lines (Figure 1B).

\section{Salinomycin inhibits the ligand independent activation of ERa}

The underlying mechanism of the additional cytotoxic effect of salinomycin needs to be further
A

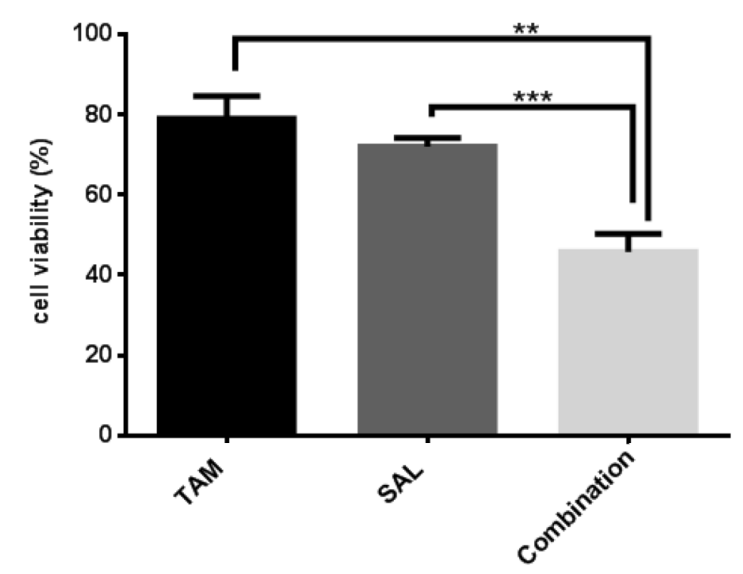

T47D

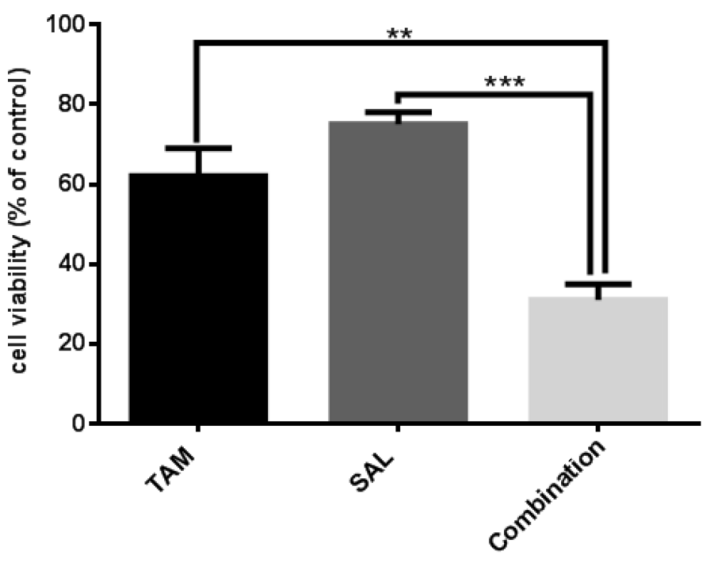

\begin{tabular}{|c|c|}
\hline Cell line & Combination index $(\mathrm{CI}){ }^{*}$ \\
\hline MCF-7 & 0,68 \\
\hline T47D & 0,30 \\
\hline
\end{tabular}

B

MCF-7

T47D

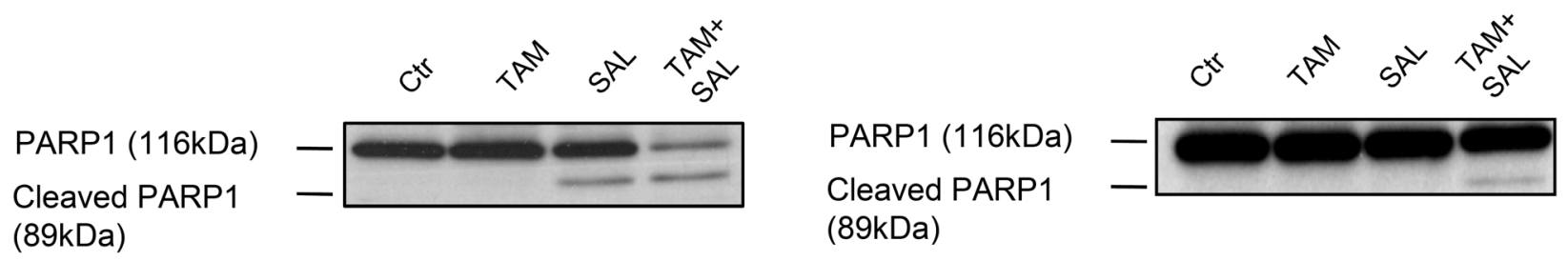

Figure 1: Cytotoxicity of combined treatment with tamoxifen and salinomycin. A. Cytotoxicity assay of treated MCF-7 and T47D cells. Cell viability was assessed upon $72 \mathrm{~h}$ treatment with $10 \mu \mathrm{M}$ tamoxifen, $0,5 \mu \mathrm{M}$ salinomycin or the combination using Cell Titer Glo ${ }^{\circledR}$ reagent. $\mathrm{N}=6$; * $\mathrm{CI}<1$ : synergistic, $\mathrm{CI}=1$ : additive, $\mathrm{CI}>1$ antagonistic. B. PARP1 cleavage. Western blot analysis of two luminal A breast cancer cell lines MCF-7 and T47D upon $72 \mathrm{~h}$ treatment with $10 \mu \mathrm{M}$ tamoxifen, $0,5 \mu \mathrm{M}$ salinomycin or their combination. Total cell lysates were analyzed for PARP1 cleavage, an apoptosis marker. p-values: ${ }^{*} 0,05 ; * * 0,01 ; * * * 0,001 ; * * * * 0,0001$. 
elucidated because MCF-7 and T47D show no overexpression of $\mathrm{ABC}$ transporters as well as cancer stem cell-like properties. Therefore, we investigated the important signaling pathways in luminal A breast cancer cells by western blotting upon $72 \mathrm{~h}$ treatment with tamoxifen, salinomycin or the combination.

Tamoxifen treatment increases the protein expression of $\mathrm{ER} \alpha$ reflecting a common mechanism to circumvent target inhibition. Salinomycin treatment on the other hand is not changing the expression level of ER $\alpha$ but importantly the combination is decreasing the amount of ER $\alpha$ compared to control (Figure 2A).

Another important pathway in hormone receptor positive breast cancer is the ligand independent activation of ER $\alpha$ by Egfr-family members which represents an intrinsic resistance mechanism to endocrine therapy. For that reason, the protein expression of Egfr, Her2, Her3 and Her4 were analyzed by western blotting. We found that single tamoxifen treatment increases the expression levels of Her2 (in both cell lines) and Her3 as well as Her4

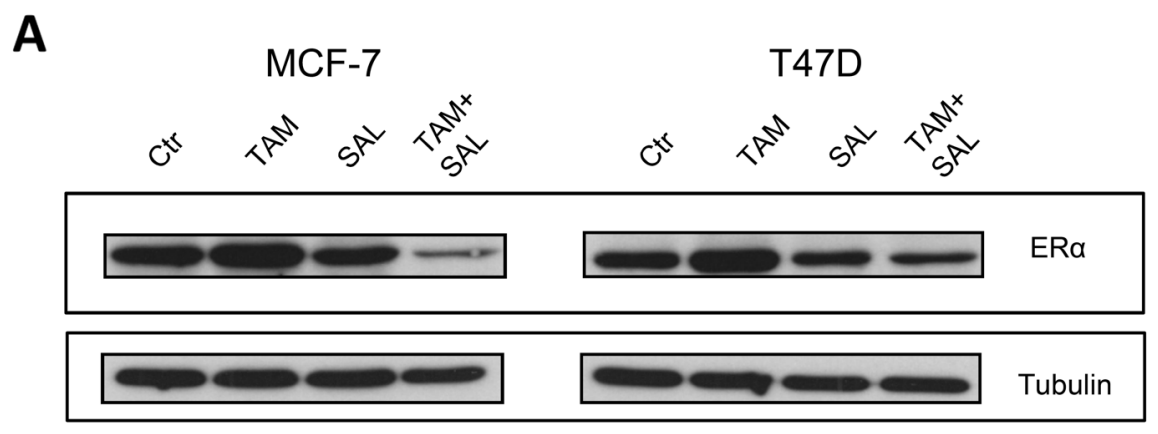

B
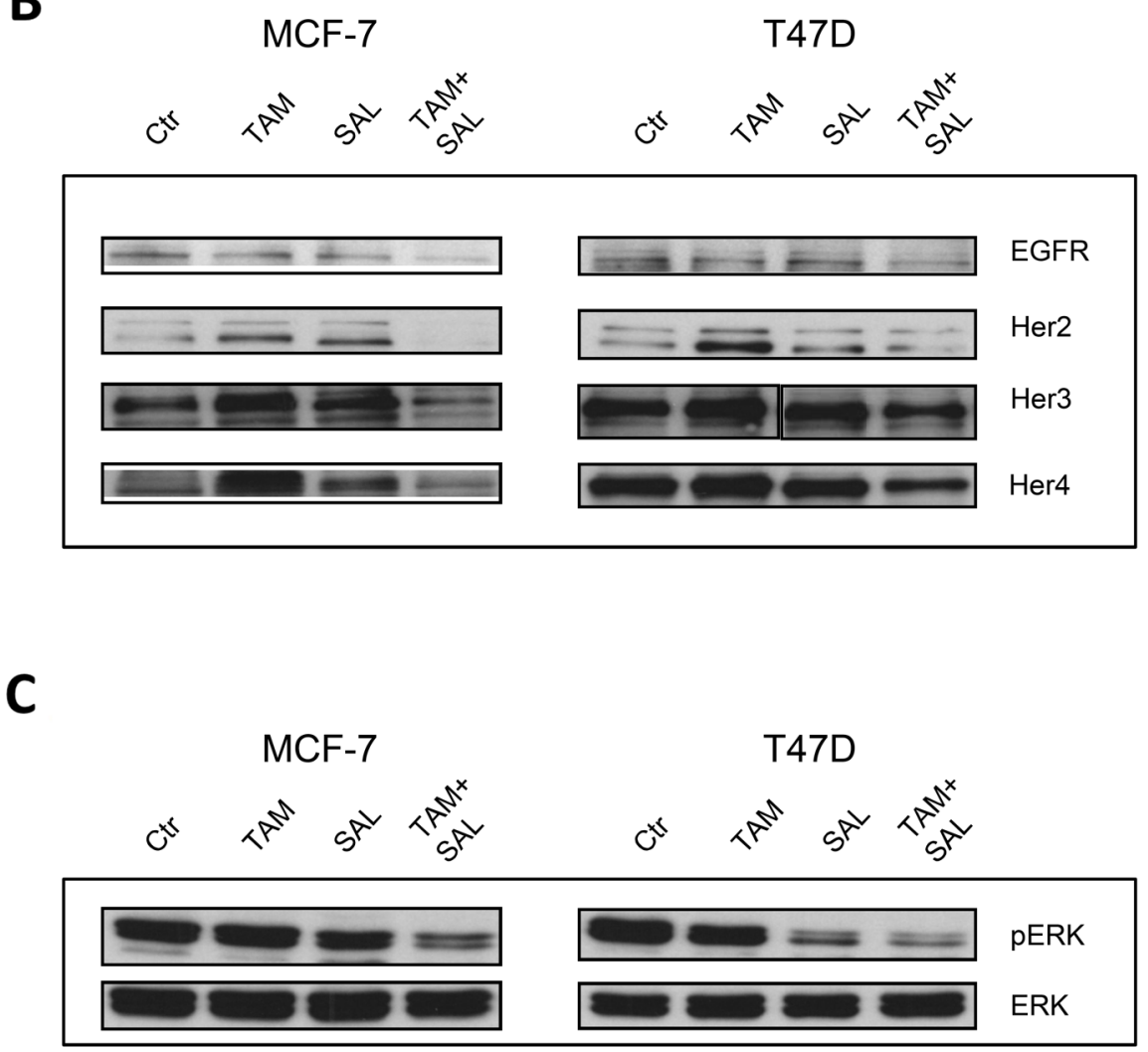

Figure 2: Characterization of cytotoxicity. Western blot analysis of two luminal A breast cancer cell lines MCF-7 and T47D upon $72 \mathrm{~h}$ treatment with $10 \mu \mathrm{M}$ tamoxifen, $0,5 \mu \mathrm{M}$ salinomycin or the combination. Tubulin was used as loading control and is representative for all blots. A. Expression of ER $\alpha$ upon treatment. To investigate the protein expression of ER $\alpha$ total cell lysates were utilized. B. Ligand independent signaling of ER $\alpha$. Total cell lysates were analyzed for protein expression levels of Egfr-family members. C. Ligand independent signaling of Erk1/2. To investigate the protein expression of Erk1/2 total cell lysates were utilized. 
in MCF-7 cells compared to untreated cells. No changes were detectable in the protein expression of Egfr-family members upon salinomycin treatment. Noteworthy, by applying the combination of tamoxifen and salinomycin the expression level of all Egfr-family members was reduced. We additionally analyzed the gene expression by qPCR and observed a slight reduction after $72 \mathrm{~h}$ in all treatment conditions (Supplementary Figure S1). As a consequence of the reduced RTK expression downstream Erk phosphorylation was diminished, too (Figure 2B and 2C).

These results demonstrate that a combination of tamoxifen with salinomycin decreased the expression of RTKs and efficiently inhibits the ligand independent signaling which is usually turned on after single tamoxifen treatment. By combining tamoxifen with salinomycin it is possible to circumvent one major tamoxifen resistance mechanism.

\section{Salinomycin facilitates the lysosomal degradation of RTKs}

To elucidate the mechanism how the ionophore salinomycin is able to interfere with the ligand independent activation of ER $\alpha$ via Egfr-family members we analyzed the cellular distribution of Egfr and Her2 during salinomycin treatment with spinning disk microscopy. We transfected Egfr and Her2 with a GFPtag into MCF-7 breast cancer cells to monitor their cellular fate upon salinomycin treatment. Interestingly, we found that salinomycin induces a strong co-localization of these RTKs with the lysosomal marker lysotracker suggesting an enhanced lysosomal degradation after $24 \mathrm{~h}$ of salinomycin treatment. This is further supported by the quantification of the co-localization with the M1-coefficient (Figure 3A). When cells were stimulated with EGF and treated with salinomycin the receptor disappeared from the membrane and almost completely accumulated in lysosomes after addition of salinomycin. In contrast, without EGF stimulation cells still displayed a cell surface staining indicating a balance between lysosomal degradation and de novo synthesis of these RTKs (Figure 3B).

Salinomycin is able to increase the intracellular calcium level as previously shown in neurons [25]. This elevated calcium level, among other factors, is responsible for enhanced endocytosis and premature fusion of lysosomes with endosomes [26, 27]. Thus, we wanted to elucidate whether salinomycin treatment also augments the cytosolic calcium level in breast cancer cells. Our results demonstrate that the intracellular calcium level is significantly increased in MCF-7 cells upon salinomycin treatment as observed by a Fluo-3-AM staining (Figure 3C). By applying lysotracker we found an increased number of lysosomes accordingly.

They also seem to be stalled and are no longer transported within the cytoplasm, as depicted in a time projection and videos by live cell imaging of salinomycintreated HeLa cells (Figure 3D and Supplementary Figure S2). Taken together, these results show that salinomycin reduces the overall protein amount of the Egfr-family by enhanced lysosomal degradation. Furthermore, the salinomycin-triggered elevated cytosolic calcium level leads to pre-mature fusion of endosomes with lysosomes and accounts for decreased RTK expression.

\section{Sequential tamoxifen treatment of MCF7 cells mimics luminal A breast cancer resistance}

Tamoxifen and other SERMS are considered as first-line treatment of ER $\alpha$-positive breast cancer. Nevertheless, resistance to endocrine therapy occurs in about $40 \%$ of these breast cancer patients causing tumor relapse. As salinomycin displayed beneficial properties when combined with tamoxifen, we generated a tamoxifen resistant model cell line to further investigate the efficacy of the combination.

We repeatedly treated MCF-7 breast cancer cells with tamoxifen (these cells are termed MCF-7 TAM-R6 in the following). After six treatment cycles the sensitivity to tamoxifen was determined. In MCF-7 TAM-R6 cells the $\mathrm{IC}_{50}$ was $1,5 \mathrm{x}$ higher compared to parental MCF-7 cells reflecting acquired tamoxifen resistance (Figure 4A). Moreover, we observed a decreased mRNA level as well as protein amount of estrogen receptor alpha $(\mathrm{ER} \alpha)$ in MCF-7 TAM-R6 cells (Figure 4B).

As tamoxifen binds to ER $\alpha$ one reason for resistance to endocrine therapy is the loss of its target. We further analyzed the ER $\alpha$ pathway in MCF-7 TAM-R6 by utilizing a luciferase reporter plasmid with a promotor, containing estrogen responsive elements, to monitor ER $\alpha$-mediated gene transcription. By comparing parental MCF-7 cells with tamoxifen resistant cells, we observed that the ER $\alpha$ signaling is significantly diminished in MCF-7 TAM-R6 cells (Figure 4C). Additionally the expression level of Egfr in parental MCF-7 and MCF-7 TAM-R6 was investigated. Since the protein amount of Egfr was increased in tamoxifen resistant cells, the ligand independent activation of ER $\alpha$ via Egfr in MCF-7 TAM-R6 cells plays an even more important role than in parental MCF-7 cells (Figure 4D).

Besides ligand independent activation, tamoxifen resistance can be implemented by a variety of further molecular resistance mechanisms. Amongst them are the increase of efflux pumps as well as the appearance of so called cancer stem cells (CSC). To further characterize MCF-7 TAM-R6 cells the mRNA levels of two ABCtransporters, multidrug resistance protein 1 (MDR1) and breast cancer resistance protein (BCRP1), were examined.

We observed that repeated tamoxifen treatment augments the expression of both multidrug resistance pumps causing an increased efflux of drugs and thus acquired resistance to tamoxifen (Figure 4E). In order to 
investigate the functionality of these ABC-transporters an efflux assay with rhodamine was performed. We could show that the efflux of rhodamine after $3 \mathrm{~h}$ was increased in tamoxifen resistant cells compared to parental MCF-7 (Figure 4F).

By investigating the expression level of the three crucial stem cell markers Sox2, Nanog and Oct4, we want to provide evidence for the existence of cancer stem cell-like traits in tamoxifen resistant cells, which are known to generate drug resistance. Six treatment cycles of tamoxifen increased the mRNA levels of Nanog and Oct4 in MCF-7 TAM-R6 significantly, whereas no change in the Sox2 expression was observed (Figure 4G).

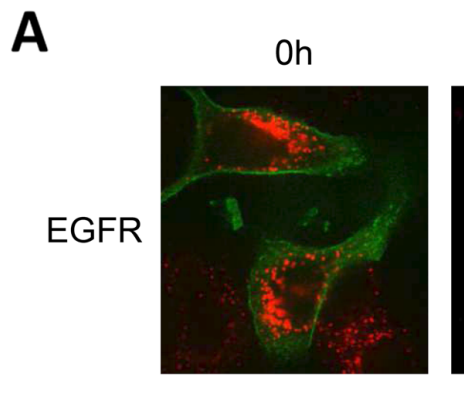

3h SAL
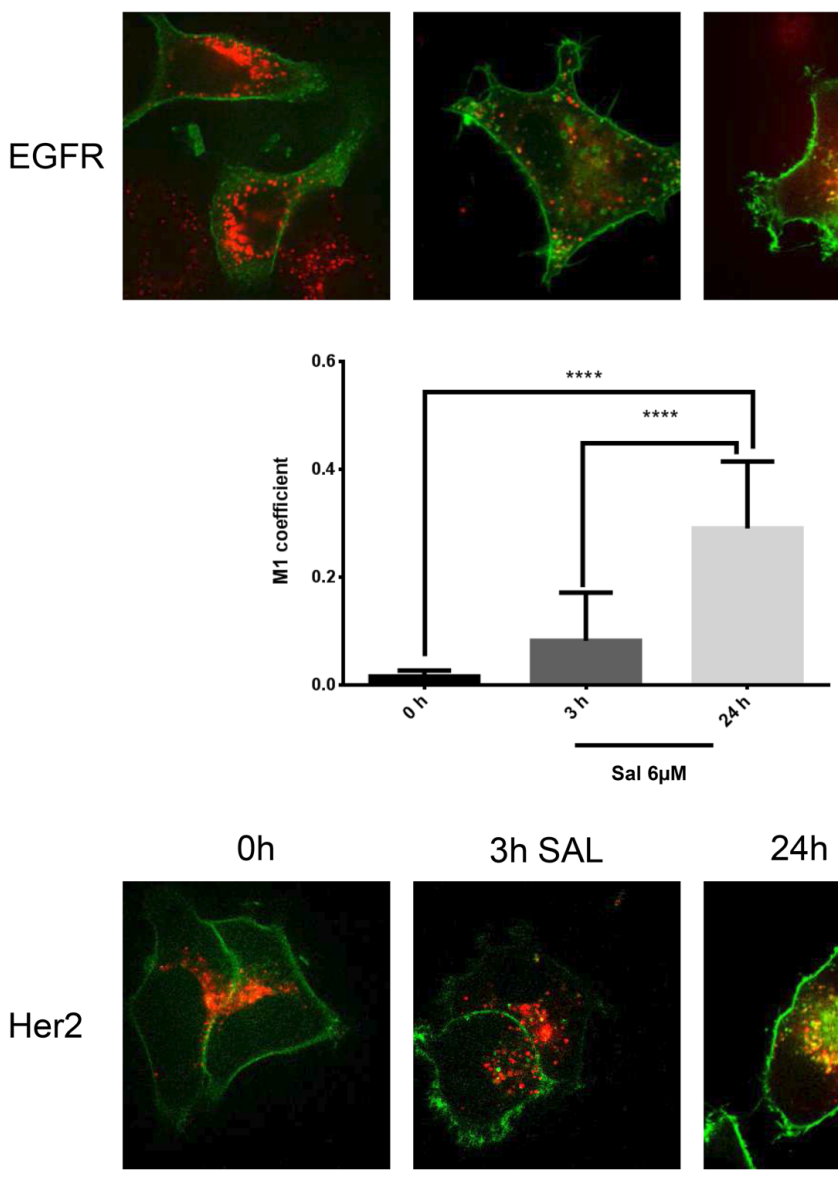

3h SAL
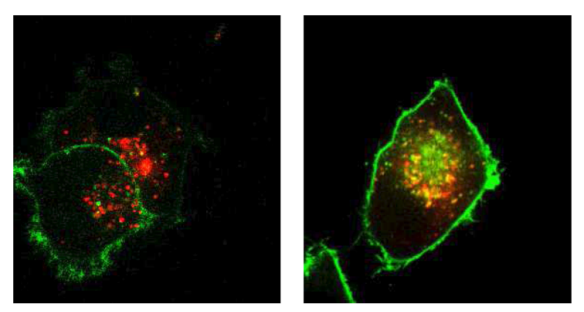

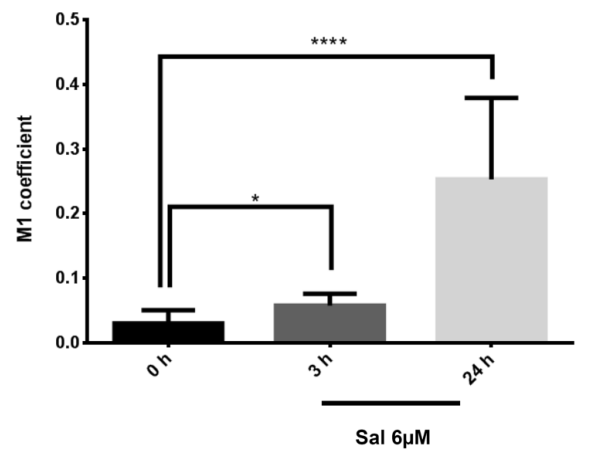

Figure 3: Endocytosis of Egfr-family members is altered upon salinomycin treatment. A. Egfr and Her2 accumulate in lysosomes MCF-7 cells were transfected with Egfr-eGFP or Her2-eGFP plasmid. Receptor-GFP expressing cells were imaged 48-72 hours after transfection by spinning disk microscopy. To detect the effect of salinomcyin on receptor trafficking, salinomycin was added at $6 \mu \mathrm{M}$ concentration $3 \mathrm{~h}$ and $24 \mathrm{~h}$ before imaging. For co-localization with lysosomes, $15 \mathrm{nM}$ lysotracker deep red was added. Co-localization was quantified by Image J JaCOP plug-in and displayed as Manders coefficient M1 (N=7-13 images per incubation time). Image size 62 $\mu \mathrm{m}$. (Continued) 
B

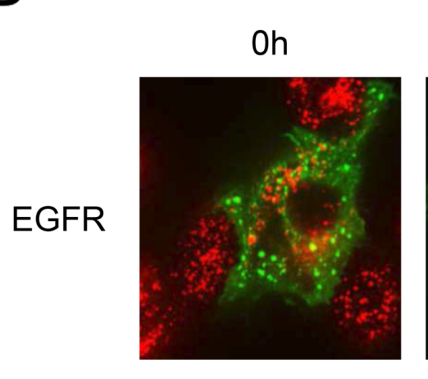

3h SAL

$+\mathrm{EGF}$

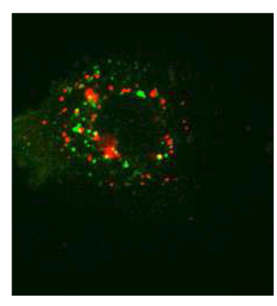

(10)

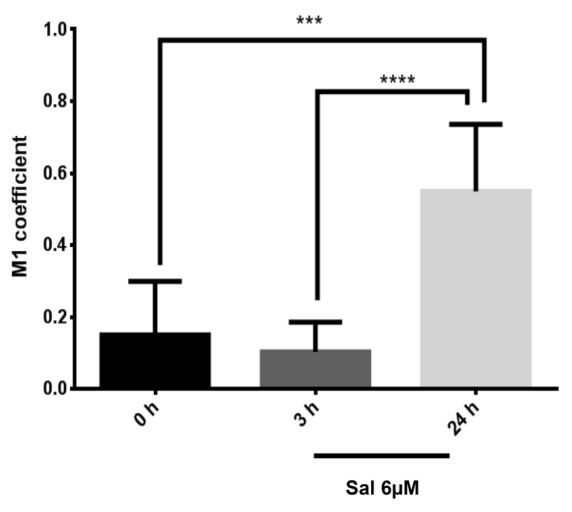

24h SAL $+\mathrm{EGF}$
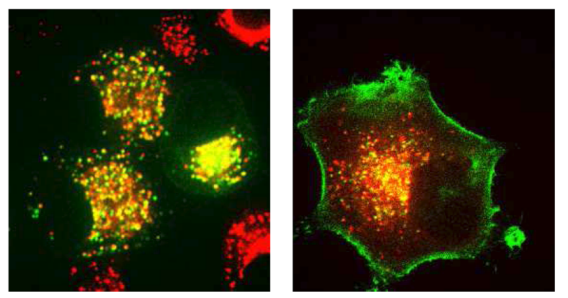

(1)

C
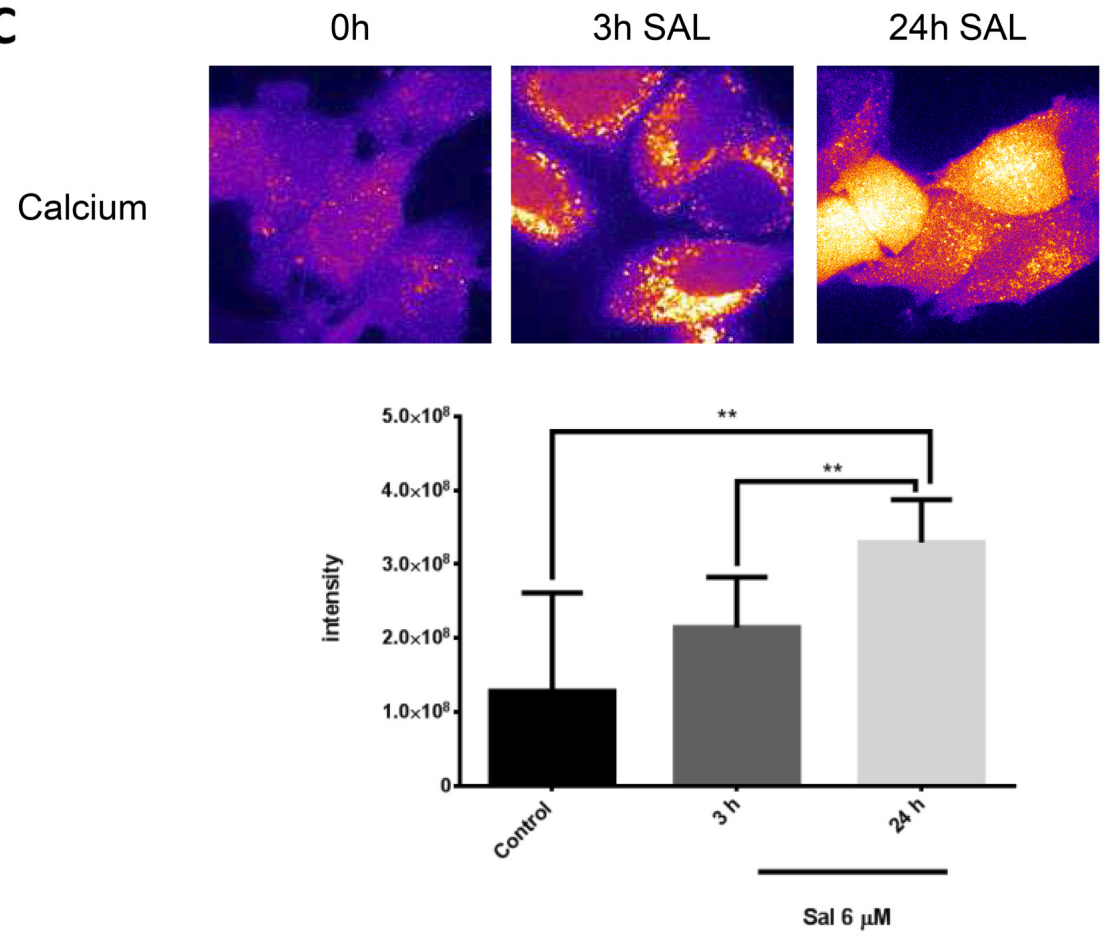

Figure 3: Endocytosis of Egfr-family members is altered upon salinomycin treatment. B. Salinomycin inhibits receptor recycling upon EGF-stimulation MCF-7 cells were transfected with Egfr-eGFP plasmid. Receptor-GFP expressing cells were imaged 4872 hours after transfection by spinning disk microscopy. To detect the effect of salinomcyin on receptor trafficking, salinomycin was added at $6 \mu \mathrm{M}$ concentration $3 \mathrm{~h}$ and $24 \mathrm{~h}$ before imaging. For co-localization with lysosomes, $15 \mathrm{nM}$ lysotracker deep red was added. To induce receptor endocytosis, $50 \mathrm{pmol} / \mathrm{ml}$ EGF was added to the cells. Co-localization was quantified by Image J JaCOP plug-in and displayed as Manders coefficient M1. (N=7-13 images per incubation time). Image size $62 \mu \mathrm{m}$. C. $\mathrm{Ca}^{2+}$-levels are elevated MCF-7 cells were pretreated with $6 \mu \mathrm{M}$ salinomycin for 3h, 24h or kept without salinomycin treatment. 1 hour before imaging, $6 \mu \mathrm{M}$ Fluo-3-AM was added to the cells. To quantify the Fluo-3-AM fluorescence in the cells, digital image analysis was performed in ImageJ. Mean values of all evaluated cells are presented ( $\mathrm{N}=8-10$ images for each incubation time). (Continued) 

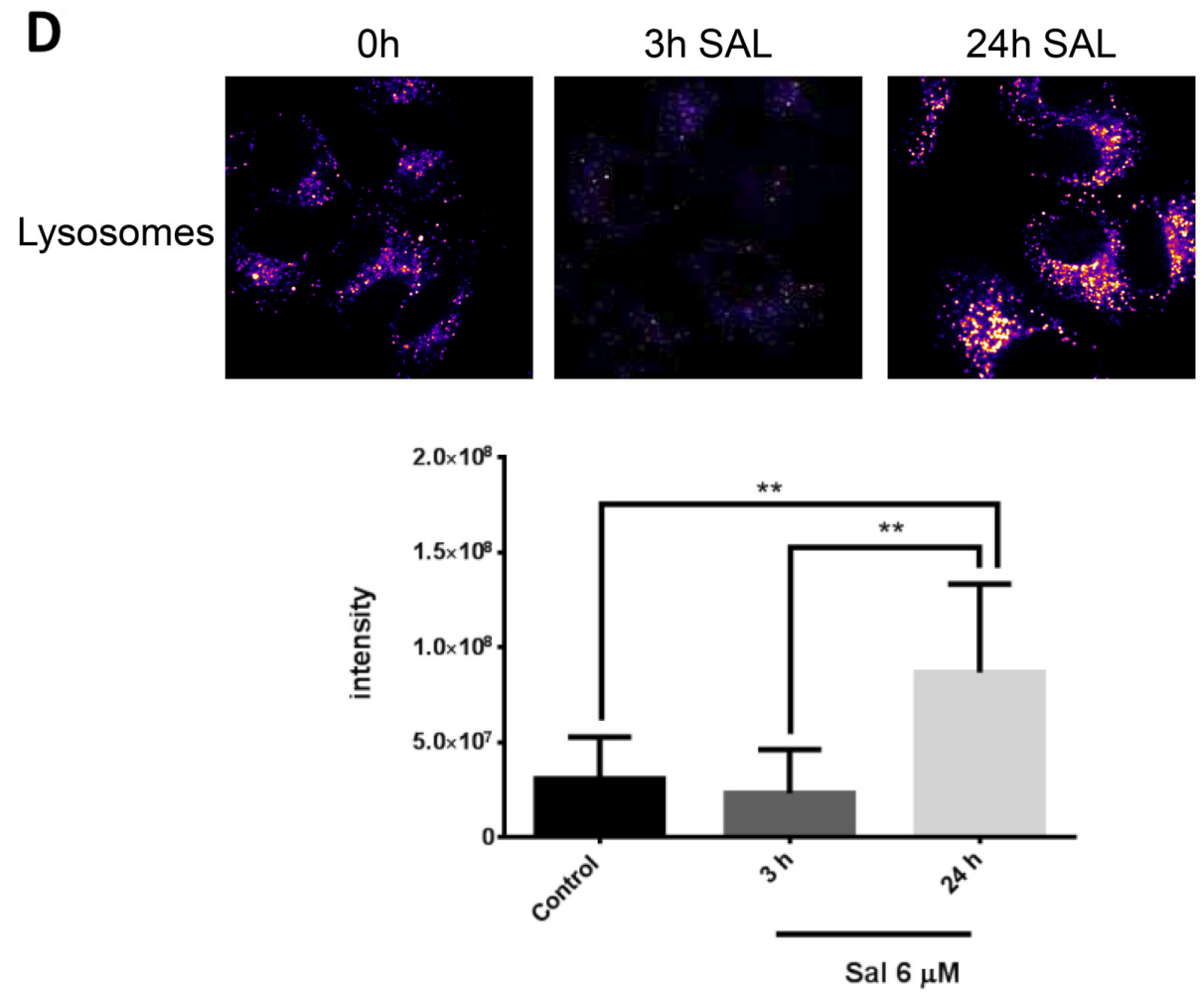

Figure 3: (Continued) Endocytosis of Egfr-family members is altered upon salinomycin treatment. D. Measurement of the intensity of lysosomes. MCF-7 cells were pretreated for $3 \mathrm{~h}, 24 \mathrm{~h}$ with $6 \mu \mathrm{M}$ salinomycin or kept without salinomycin treatment. 1 hour before imaging $15 \mathrm{nM}$ Lysotracker was added to the cells. Digital image analysis was utilized in ImageJ to quantify Lysotracker fluorescence in the cells. Mean values of all evaluated cells are presented ( $\mathrm{N}=8-10$ images for each incubation time) Image size $62 \mu \mathrm{m}$. p-values: $* 0,05 ; * * 0,01 ; * * * 0,001 ; * * * * 0,0001$.

To functionally prove the existence of cancer stem cells, we performed a mammosphere forming assay and determined an increased amount of formed spheroids in MCF-7 TAM-R6 cells (Figure 4H).

Thus, we validated four acquired resistance mechanisms, i.e. loss of the drug target, increased expression of multidrug resistance pumps, enhanced activity of the ligand independent signaling pathway and the occurrence of resistant CSC in our long-term molecular evolution assays.

\section{Combination of tamoxifen with salinomycin overcomes tamoxifen resistance}

Finally, we investigated whether the combination of tamoxifen and salinomycin is also superior to the respective single treatments in the tamoxifen resistant MCF-7 TAM-R6 cells. We first examined the effect of salinomycin on cell viability of MCF-7 TAM-R6.

Remarkably, tamoxifen resistant cells MCF-7 TAM-R6 are four times more sensitive to salinomycin than parental MCF-7 cells according to their $\mathrm{IC}_{50}$ values (Supplementary Figure S3). The combination of both drugs is more efficient in resistant cells than in sensitive ones and shows moreover a synergistic effect [22-24]
(Figure 5A). As resistance of tumor cells to a certain drug is not only reflected in short term cell survival, a long-term assay represents efficacy of drugs in another way. Thus, we performed a clonogenic assay where cells could recover for two weeks after the initial $72 \mathrm{~h}$ drug treatment. We observed an enhanced colony formation in tamoxifen resistant cells, reflecting increased proliferation. In both cell lines, i.e. MCF-7 and MCF-7 TAM-R6, the combination of the drugs shows highest efficacy (Figure 5B).

In summary, we have shown that salinomycin cotreatment is able to overcome tamoxifen resistance in MCF-7 TAM-R6 cells.

\section{DISCUSSION}

Recent findings revealed that salinomycin, a wellknown monocarboxylic polyether antibiotic, might be a promising drug in cancer therapy because it is able to eradicate cancer stem cells [11] and to overcome ABCtransporter mediated resistance due to its interference with cell membranes [10]. To figure out whether salinomycin is a suitable additive drug in tamoxifen treatment, it had to be elucidated whether salinomycin co-treatment provides increased antitumoral efficacy. Here, we show that the combinational treatment augments cytotoxicity 


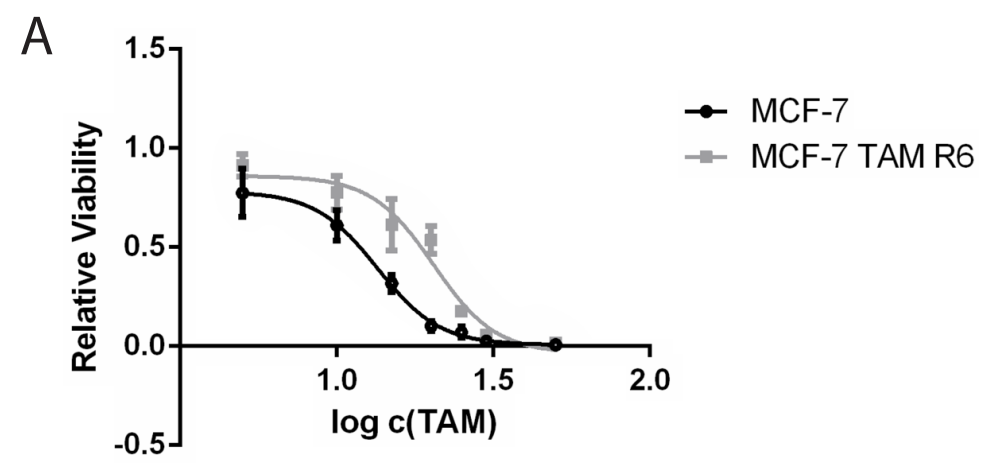

\begin{tabular}{|l|l|}
\hline Cell line & $\mathrm{IC}_{50}$ \\
\hline MCF-7 & $13,49 \mu \mathrm{M}$ \\
\hline MCF-7 TAM-R6 & $20,37 \mu \mathrm{M}$ \\
\hline
\end{tabular}

B
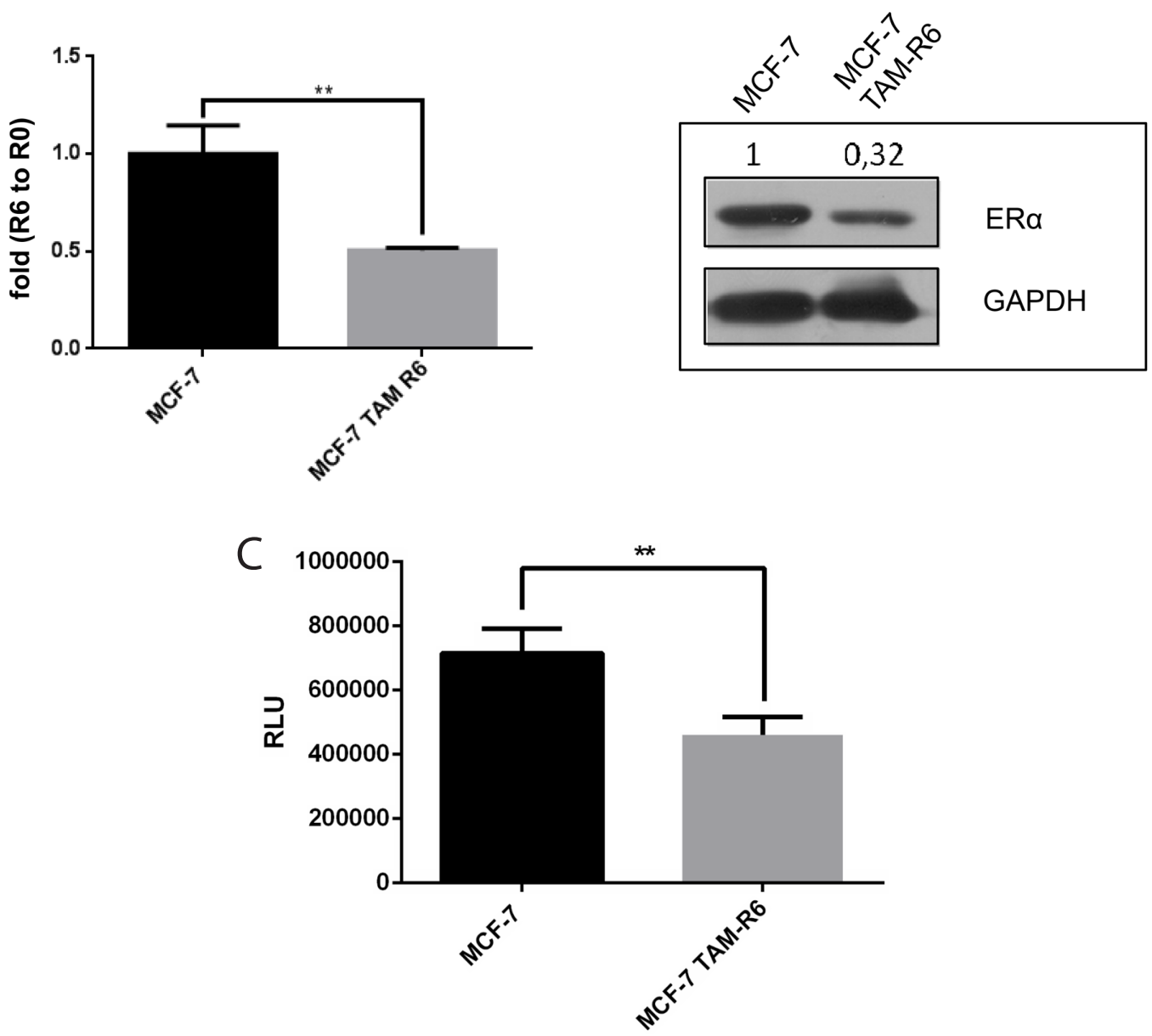

Figure 4: Tamoxifen resistance. MCF-7 cells were treated in several rounds with $10 \mu \mathrm{M}$ tamoxifen for $72 \mathrm{~h}$ followed by recovery phase until a confluence of $80 \%$. Cells that received either no treatment (MCF-7) or six treatment rounds (MCF-7 TAM-R6) were harvested for the following experiments. A. $\mathrm{IC}_{50}$ of tamoxifen in resistant cells is increased. Cytotoxicity assay of tamoxifen resistant MCF-7 cells. MCF7 TAM-R6 cells were treated with indicated concentrations of tamoxifen for $72 \mathrm{~h}$. Subsequently cell viability was assessed by Cell Titer Glo ${ }^{R}$ Assay (Promega). N=3. B. ER $\alpha$ expression in MCF-7 TAM-R6 is reduced. Quantitative RT-PCR analysis of ER $\alpha$ level in MCF-7 vs. MCF-7 TAM-R6 cells. Expression levels were normalized to parental MCF-7 cells. N=3 Protein expression of ER $\alpha$ in parental MCF-7 as well as MCF-7 TAM-R6 were analyzed by western blotting. C. Analysis of ER $\alpha$ signaling Parental MCF-7 and MCF-7 TAM-R6 cells were transfected with 3x-ERE-TATA-Luc plasmid (Addgene \#11354) and serum-starved for $12 \mathrm{~h}$. Next, cells were stimulated with $1 \mathrm{nM}$ estradiol for $30 \mathrm{~min}$ and subsequently treated with $10 \mu \mathrm{M}$ tamoxifen for $12 \mathrm{~h}$. The luciferase signal was analyzed and normalized to control. p-values: $* 0,05 ; * * 0,01 ; * * * 0,001 ; * * * * 0,0001$. (Continued) 


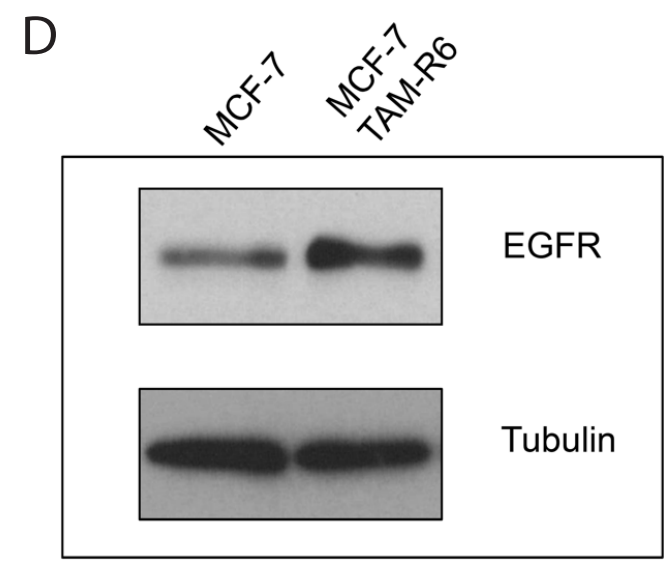

E

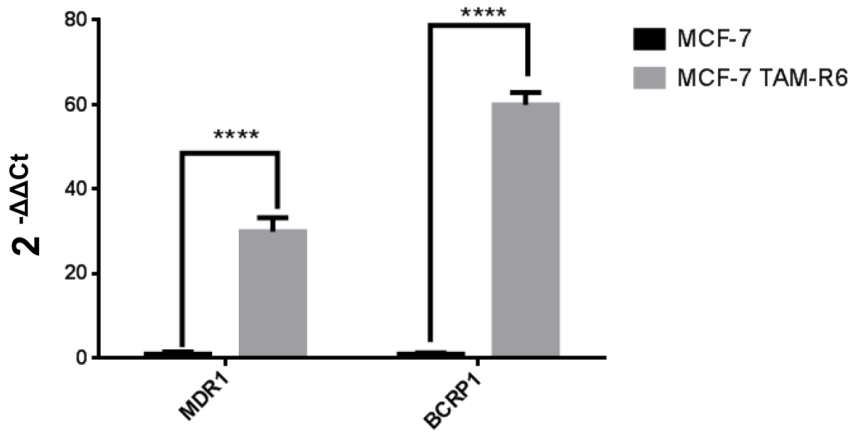

$\mathrm{F}$

MCF-7

MCF-7 TAM-R6
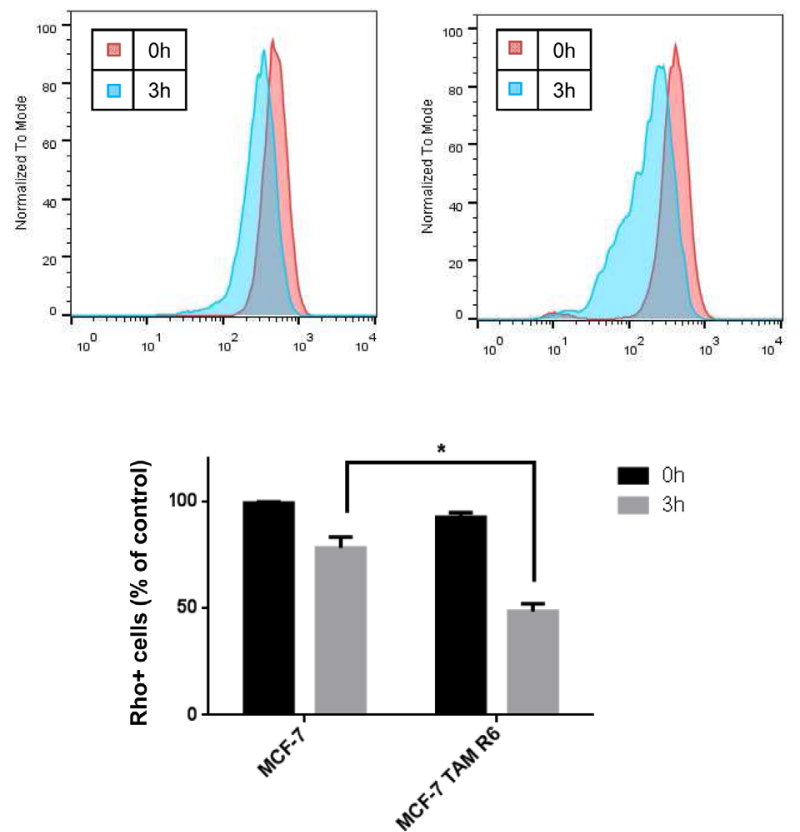

Figure 4: Tamoxifen resistance. D. Egfr expression in MCF-7 TAM-R6 is increased. Western blot analysis of parental MCF-7 and MCF-7 TAM-R6 total cell lysates was performed to investigate the expression level of Egfr. Tubulin was used as loading control. E. Expression of $\mathrm{ABC}$ transporters is enhanced in tamoxifen resistant cells qPCR was utilized to examine the mRNA expression level of multiple-drug-resistance protein 1 (MDR1) and breast cancer resistance protein 1 (BCRP1), two ABC-transporters that are frequently causing drug resistance. F. Rhodamine123 efflux assay. The dye Rhodamine123 is a well-known target of ABC-transporters. Therefore, parental MCF-7 as well as MCF-7 TAM-R6 cells were treated for 30 minutes with $0,2 \mu \mathrm{g} / \mathrm{ml}$ Rhodamine 123 . Afterwards cells were washed to eliminate Rhodamine123, resuspended in the corresponding medium. Finally, flow cytometry was performed $1 \mathrm{~h}, 2 \mathrm{~h}$ and $3 \mathrm{~h}$ later to determine the efflux activity. Data were normalized to untreated samples. (Continued) 

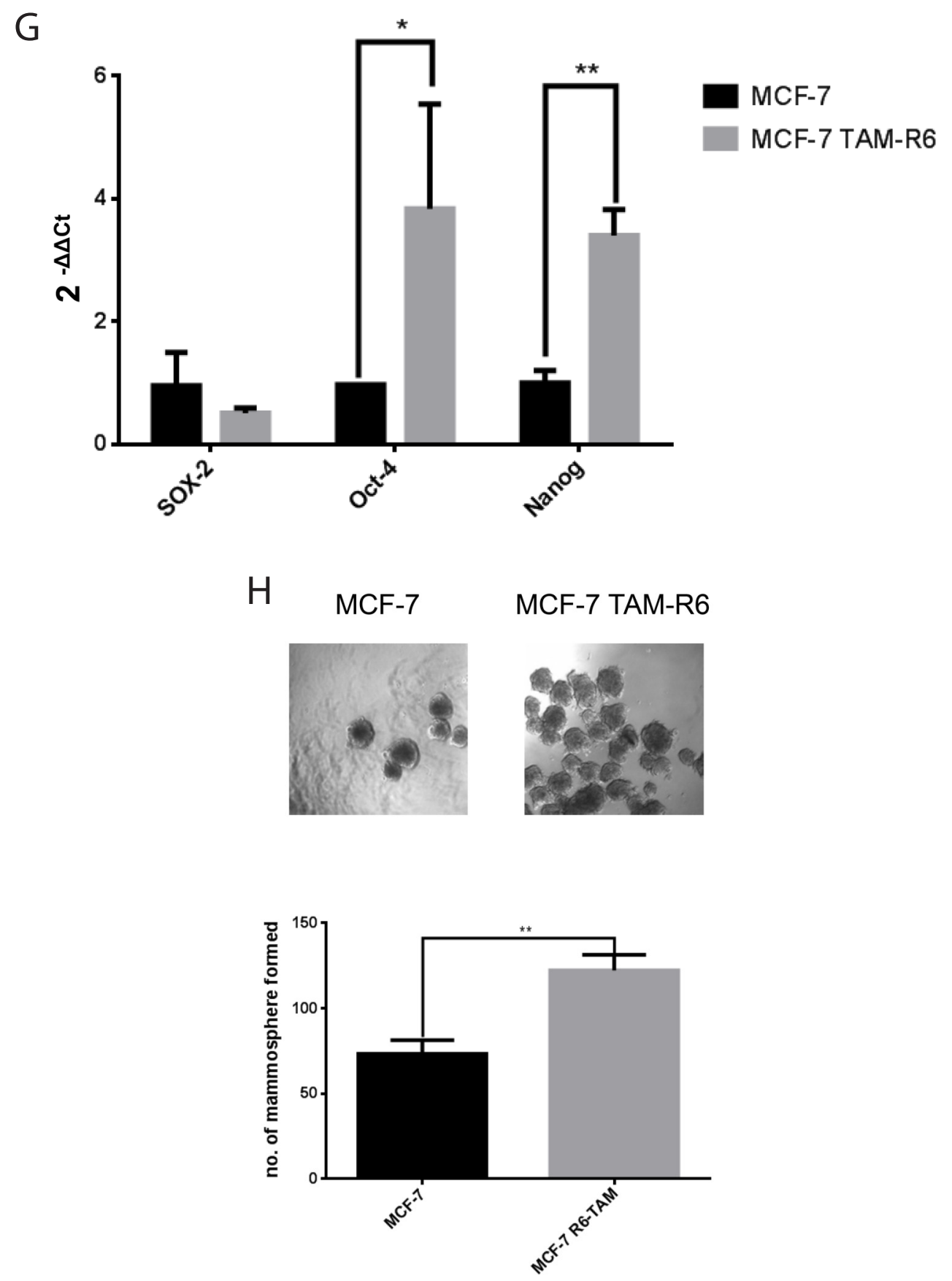

Figure 4: (Continued) Tamoxifen resistance. G. Expression of cancer stem cell marker is enhanced in MCF-7 TAM-R6 compared to parental cells. To determine the occurrence of cancer stem cells in tamoxifen resistant cells three prominent CSC marker SOX-2, Oct-4 and Nanog were investigated by qPCR. H. Mammosphere formation is increased in tamoxifen resistant cells. Another possibility to analyze stem cell properties in cancer cell populations is the mammosphere forming assay. Therefore, $10 \times 10^{5} \mathrm{c} / \mathrm{w}$ parental MCF-7 as well as MCF7 TAM-R6 were seeded in a non-adherent 96-well plate and formed spheroids were counted 7 days afterwards.

synergistically and reduces the expression of all Egfrfamily members. It was further detected that Egfr as well as Her2 accumulated in lysosomes upon single salinomycin treatment though we observed no significant difference in protein levels but decreased mRNA levels. These facts might reflect enhanced de novo protein biosynthesis of the RTKs, compensating the lysosomal degradation induced by salinomycin.
By additionally applying tamoxifen, the ER $\alpha$ signaling is inhibited leading to the induction of an escape mechanism, i.e. the ligand independent activation of ER $\alpha$ via the Egfr-family. Subsequently, RTK signaling has to become more active reflecting a stimulus that might lead to enhanced receptor accumulation in endosomes.

Recently, Boehmerle and Endres have demonstrated increased cytosolic $\mathrm{Ca}^{2+}$-levels in neuronal cells upon 


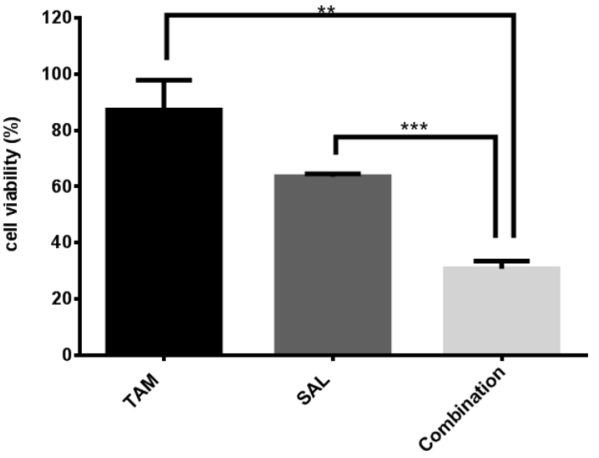

\begin{tabular}{|c|c|}
\hline Cell line & Combination index $(\mathrm{Cl})^{*}$ \\
\hline MCF-7 TAM-R6 & 0,33 \\
\hline
\end{tabular}

B

Control

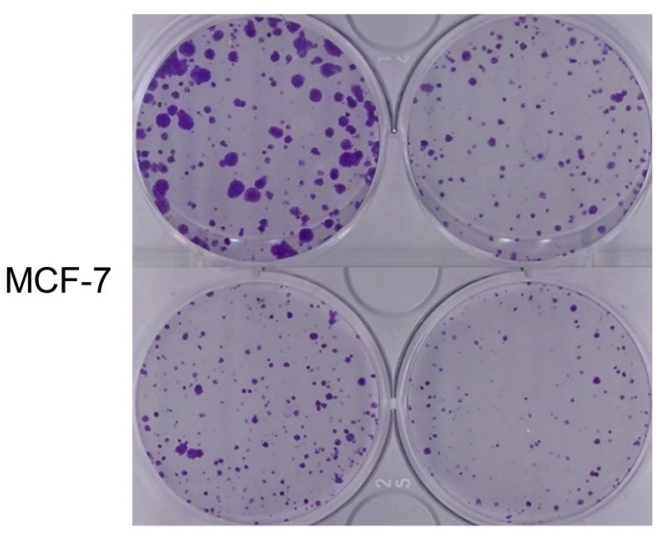

SAL Combination
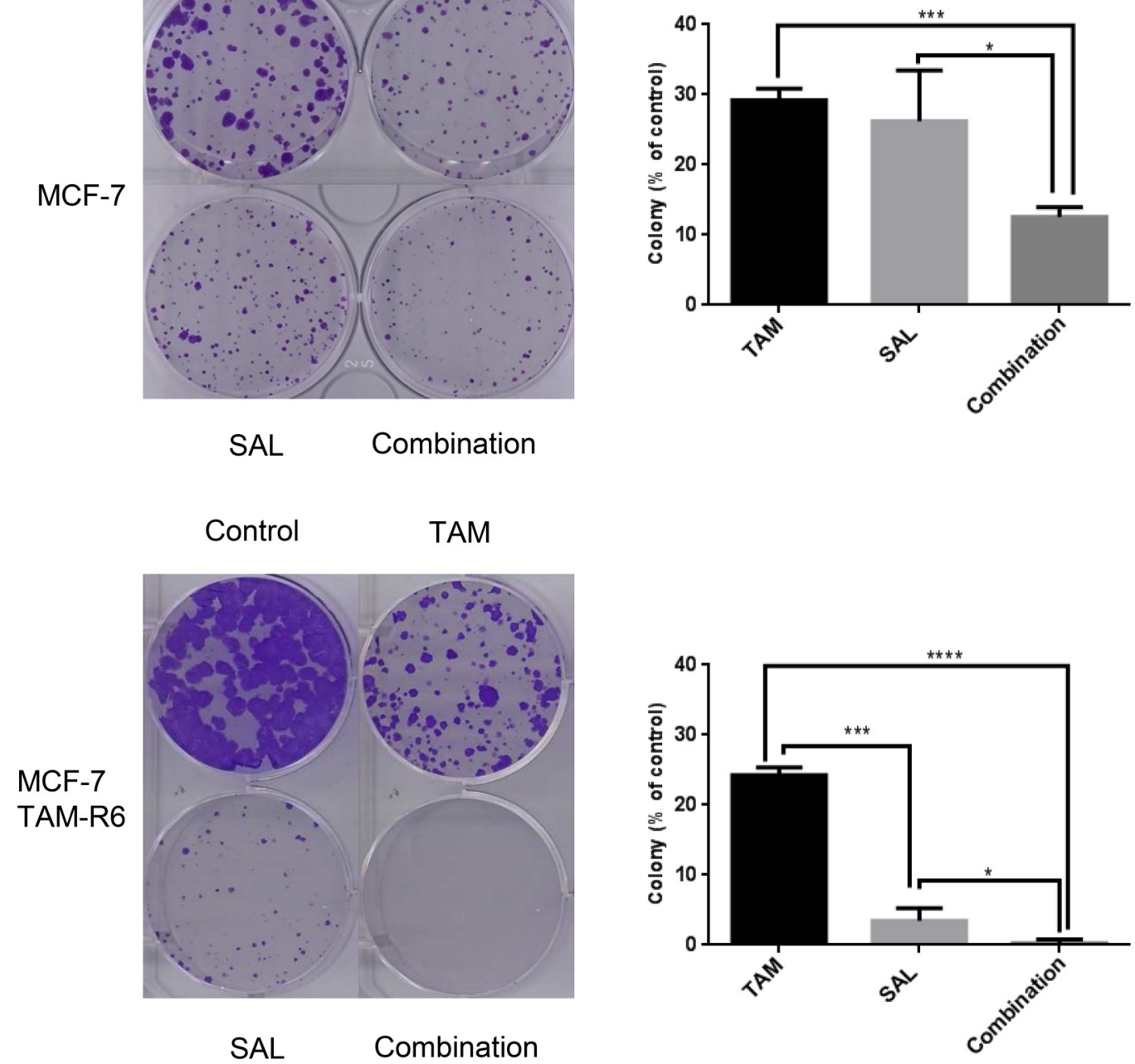

Figure 5: Salinomycin acts synergistic with tamoxifen to circumvent tamoxifen resistance. A. Combinatorial treatment of

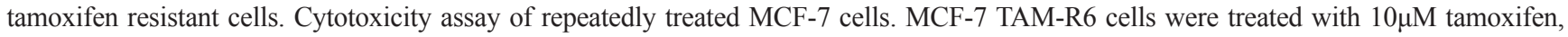
$0,5 \mu \mathrm{M}$ salinomycin or their combination for $72 \mathrm{~h}$. Subsequently cell viability was assessed by Cell Titer Glo ${ }^{\circ}$ Assay. $\mathrm{N}=3 ; * \mathrm{Cl}<1$ : synergistic, $\mathrm{CI}=1$ : additive, $\mathrm{CI}>1$ antagonistic. B. Clonogenic assay - long-term resistance. To analyze long-term resistance, cells were seeded and incubated for $24 \mathrm{~h}$ prior to $72 \mathrm{~h}$ of treatment with $20 \mu \mathrm{M}$ tamoxifen, $10 \mu \mathrm{M}$ salinomycin or their combination. Cells were then grown for 14 days, fixed and stained. Surviving colonies were analyzed by ColonyArea (Image J plug-in), N=3 p-values: ${ }^{*} 0,05 ;{ }^{* *} 0,01 ;{ }^{* * *} 0,001 ; * * * * 0,0001$. 
salinomycin treatment [25]. This was ascribed partly to $\mathrm{Ca}^{2+}$-efflux from mitochondria and partly to increased $\mathrm{Ca}^{2+}$ influx via the plasmamembrane by $\mathrm{Na}^{+} / \mathrm{Ca}^{2+}$ exchangers. These increased cytosolic $\mathrm{Ca}^{2+}$-levels induced by salinomycin treatment, facilitate premature fusion of endosomes and lysosomes [25]. Consequently, lysosomal degradation of RTKs could be enhanced causing decreased protein levels (Figure 6). To which extent the general trafficking and recycling of membrane receptors is affected by salinomycin has to be elucidated in future studies.

When specifically hampering the ligand independent pathway by lapatinib, a Egfr- and Her2-inhibitor, we observed a beneficial effect of the combination as well (data not shown). However, combining tamoxifen and salinomycin displayed even greater efficacy. Thus, the combination is more potent due to additional toxic effects of salinomycin like enhanced $\mathrm{Ca}^{2+}$-influx or interference with the plasma membrane.
Even though most ER $\alpha$ positive breast tumors initially respond to endocrine therapy, a majority relapses after several years and turns insensitive to tamoxifen treatment [28]. Drug resistance mechanisms can be distinguished between longterm resistance (acquired), which we observe after several treatment cycles, and short-term effects (intrinsic resistance). In this study, we mimicked acquired endocrine resistance by repeated tamoxifen treatment and demonstrated the existence of three major resistance mechanisms, namely, MDRs, CSC and the loss of its target, i.e. ER $\alpha$. Intrinsic drug resistance was studied by $72 \mathrm{~h}$ of tamoxifen treatment and revealed the ligand independent signaling by RTKs. By inhibiting ER $\alpha$, SERMs induce an escape mechanism via a cross-talk with Egfr-family members [7-9, 29-34]. Salinomycin directly interferes with this pathway and thus is complementing the tamoxifen effect. A change in cancer stem cell marker (CSM) expression and the expression of multiple drug resistance (MDR) proteins was not observed for short term treatment.
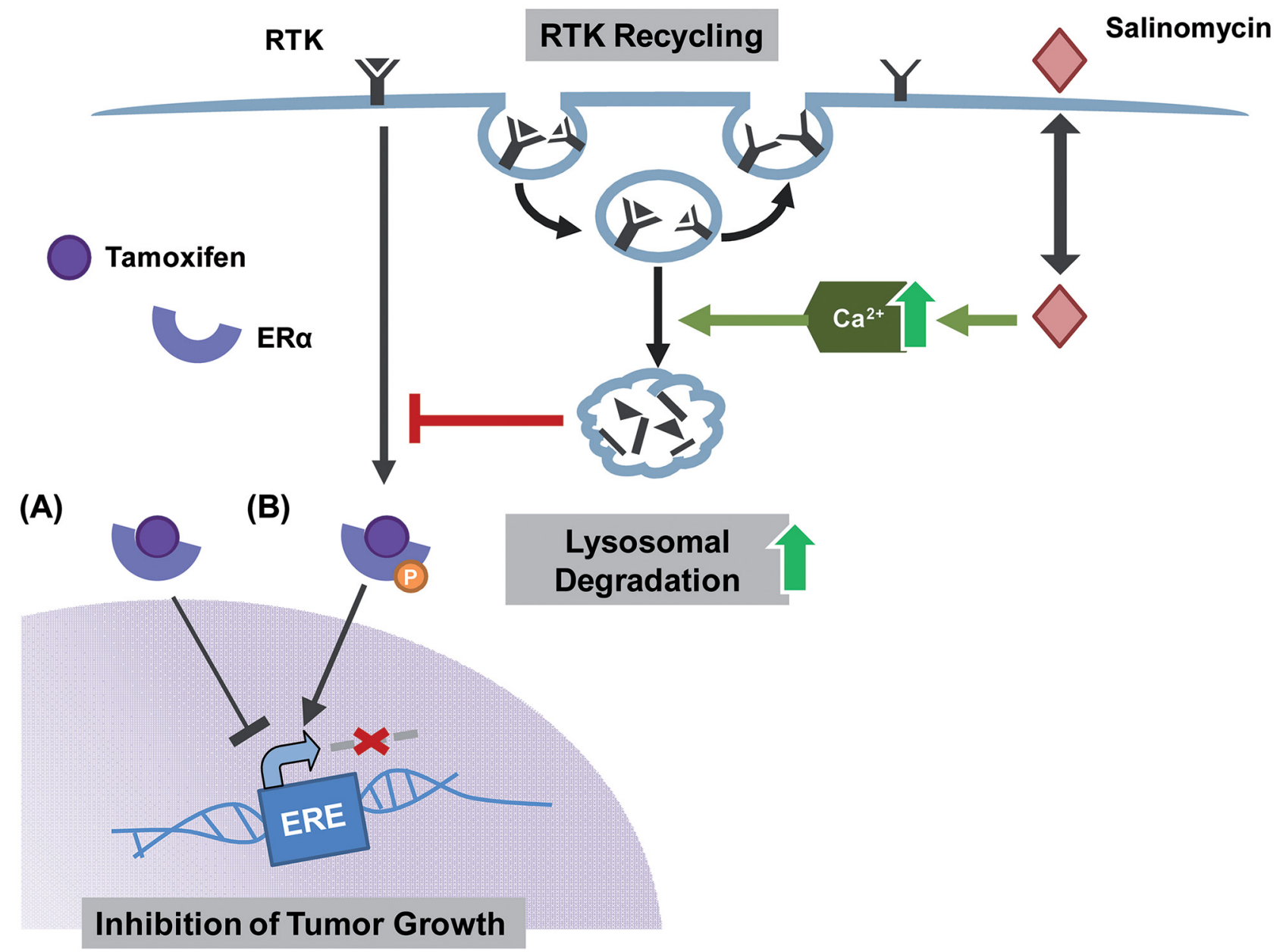

Figure 6: Hypothesis how salinomycin hampers the ligand independent activation of ER $\alpha$. Tamoxifen binds the ER $\alpha$ and subsequently inhibits the transcription of estrogen responsive genes responsible for tumor growth (A) Luminal A tumors however are able to circumvent this blockage via the ligand independent phosphorylation of the ER $\alpha$ by enhanced RTK signaling (B) A combinatorial treatment of tamoxifen-sensitive as well as -resistant cells with tamoxifen and salinomycin hampers both ways of ER $\alpha$ activation as salinomycin enhances lysosomal degradation of RTK via an increase of $\mathrm{Ca}^{2+}$. 
However, when analyzing long-term resistance upon single tamoxifen treatment by the molecular evolution assay, we observed acquired resistance mechanisms, i.e. increased MDR and CSM (cancer stem cell markers). As published previously, longterm single salinomycin treatment, results in the opposite mechanisms, i.e. reduced CSM and increased MDR [35], showing the possibility of salinomycin to counteract the acquired resistance mechanism of single tamoxifen treatment.

In order to investigate the efficacy of the combination, salinomycin and tamoxifen, we examined the cell viability in tamoxifen-sensitive (MCF-7) as well as tamoxifen-resistant MCF-7 TAM-R6 cells and showed that a combined treatment is beneficial in both cases. This indicates that the combination of tamoxifen with salinomycin not only avoids intrinsic resistance to endocrine therapy but also eradicates acquired resistant breast cancer cells. Thus, we postulate a novel treatment strategy for luminal A breast cancer patients in order to prevent and to overcome tamoxifen resistance.

\section{MATERIALS AND METHODS}

\section{Cell culture and drug treatment}

The breast cancer cell lines MCF-7 and T47D were cultured according to supplier's instructions (ATCC). Cells were treated at a confluence of $80 \%$ for $72 \mathrm{~h}$ with $10 \mu \mathrm{M}$ tamoxifen (Sigma, Germany) and $0,5 \mu \mathrm{M}$ salinomycin (Sigma, Germany) separately or in combination. For this purpose, drugs were diluted in DMSO which also served as control.

\section{Cell viability assay}

To evaluate the toxicity of the two different drugs, a Cell Titer Glo® Luminescent Cell Viability Assay (Promega) was performed. Here, 3000 cells were seeded in a black clear bottom 96-well plate and 24h later treated with the corresponding drug for another $72 \mathrm{~h}$. Afterwards the reagent was added to the cells, followed by $10 \mathrm{~min}$ of incubation at room temperature. Finally plates were analyzed with a fluorescence detector.

\section{IC50 calculation}

The IC50 value for each drug was achieved by applying the following equation:

$$
\mathrm{Y}=100 /\left(1+10^{(x-\log I C 50)}\right)
$$

\section{Combination index}

The combination index (CI) of tamoxifen and salinomycin was calculated according to the following equation $[23,24]$.

$$
\begin{aligned}
& \mathrm{CI}=\frac{\mathrm{CA}, \mathrm{x}}{\mathrm{ICx}, \mathrm{A}}+\frac{\mathrm{CB}, \mathrm{x}}{\mathrm{ICx}, \mathrm{B}} \\
& \mathrm{CI} \text { : Combination Index } \\
& \mathrm{C}_{\mathrm{A}, \mathrm{x}} ; \mathrm{C}_{\mathrm{B}, \mathrm{x}} \text { : concentrations of } \operatorname{drug} \mathrm{A} \text { or } \mathrm{B} \text { used in } \\
& \text { combination to achieve } \mathrm{x} \% \text { cell viability } \\
& \mathrm{IC}_{\mathrm{x}, \mathrm{A}} ; \mathrm{IC}_{\mathrm{x}, \mathrm{B}} \text { : concentrations of single agents to } \\
& \text { achieve the same cell viability } \\
& \mathrm{CI}<1 \text { : synergy } \\
& \mathrm{CI}=1: \text { additivity } \\
& \mathrm{CI}>1 \text { : antagonism }
\end{aligned}
$$

\section{Western blot}

For immune blotting antibodies Egfr (\#2232), Her4 (\#4795), p-AKT (\#9271), p-ERK1,2 (\#9101), GAPDH (\#2118) and PARP (\#9542) from Cell Signaling Technology ${ }^{\circledR}$ were utilized.

Antibodies against Her2 (\#06-562) and Her3 (\#05-471) were bought from Merck Millipore, ER $\alpha$ (\#7207), AKT (\#8312), ERK1,2 (\#93) from Santa Cruz Biotechnology ${ }^{\circledR}$, Inc. and $\alpha$-Tubulin (\#T9026) from Sigma-Aldrich ${ }^{\circledR}$.

Cells were treated for $72 \mathrm{~h}$ and lyzed with RIPAbuffer containing $1 \%$ Triton X. $30 \mu \mathrm{g}$ protein were separated using a SDS-PAGE and afterwards transferred to a nitrocellulose membrane. After one hour blocking with NET-gelatine containing 3\% BSA, the blots were incubated overnight at $4^{\circ} \mathrm{C}$ in the corresponding primary antibody in NET-gelatine, followed by several washing steps with NET-gelatine. Subsequently membranes were incubated for one hour in horseradish peroxidase conjugated anti-mouse or anti-rabbit secondary antibodies at room temperature. After additional washing steps, detection was performed using enhanced chemiluminscence (ECL, GE Healthcare) on X-ray films.

\section{RNA isolation, cDNA synthesis and qPCR}

Total RNA was extracted and isolated from cells using miRCURY ${ }^{\mathrm{TM}} \mathrm{RNA}$ Isolation Kit (Exiqon, Denmark). RNA was then reverse transcribed to cDNA from $1 \mu \mathrm{g}$ of total RNA by using Transcriptor First Strand cDNA Synthesis Kit (Roche). Real time-PCR was then performed in Light Cycler ${ }^{\circledR} 480$ (Roche) using Master Probes Kit (Roche) and Universal Probe Library (UPL) (Roche). All protocols were performed according to the manufacturer's instructions.

RT-PCR was performed using the following primers and UPLs : ER alpha, UPL probe \#17, left primer: ATCCACCTGATGGCCAAG, right primer: GCTCCATGCCTTTGTTACTCA; SOX-2, UPL probe \#35, left primer: TTGCTGCCTCT TTAAGACTAGGA, right primer: CTGGGGCTCAAACT TCTCTC; Oct-4, UPL probe \#35, left primer: AG CAAAACCCGGAGGAGT, right primer: CCACATCG GCCTGTGTATATC; MDR1, UPL probe \#7, left 
primer: CAAGCATCTGCCAAAACCTC, right primer: CTGGGTTTCCCCCTGTAAAT; BCRP1, UPL probe \#56, left primer: TGGCTTAGACTCAAGCACAGC, right primer: TCGTCCCTGCTTAGACATCC, Nanog, UPL probe \#69, left primer: ATGCCTCACACGGAGACTGT, right primer: AGGGCTGTCCTGAATAAGCA; GAPDH, UPL probe \#45, left primer: TCCACTGGCGTCTTCACC, right primer: GGCAGAGATGATGACCCTTTT. GAPDH was used as internal control. The results were analyzed using comparative threshold cycle ( $\Delta \Delta \mathrm{CT}$ method).

\section{ER $\alpha$ reporter assay}

Cells were transfected with 3x-ERE-TATA-Luc plasmid (\#11354 Add gene) [36] using K2® Transfection System (Biontex Laboratories $\mathrm{GmbH}$ ), according to manufacturer's protocol.

\section{Spinning disk confocal microscopy}

For all imaging experiments cells were seeded in 8 well chambered $\mu$-Slides (ibiTreat, Ibidi $\mathrm{GmbH}$ ) at a density of 7000 ( 3 days before imaging) or 10000 (2 days before imaging) cells per well.

To analyze calcium concentration and lysosomes MCF-7 cells were pre-treated with $6 \mu \mathrm{M}$ salinomycin for $3 \mathrm{~h}$ or $24 \mathrm{~h}$ or kept without salinomycin treatment. 1 hour before imaging, $6 \mu \mathrm{M}$ Fluo-3-AM and 15nM Lysotracker deep red (both Molecular Probes, Life Technologies) were added to the cells. For imaging, medium was exchanged by marker-free $\mathrm{CO}_{2}$ independent medium (with or without salinomycin).

\section{Egfr and Her2 trafficking}

24 hours after seeding, cells were transfected with Egfr eGFP (Addgene plasmid 32751 [37]) or Her2 eGFP plasmid (Addgene Plasmid 39321 [38]) using the X-tremeGENE 9 DNA Transfection Reagent (Roche). Briefly, $1 \mu \mathrm{g}$ DNA were mixed at 1:3 ratio with transfection reagent in $200 \mu 1$ serum free medium and incubated for 20 minutes at room temperature. Subsequently, $5 \mu$ of the transfection mix ( $=25 \mathrm{ng}$ DNA) was pipetted to each well of the cell culture chamber.

Receptor GFP expressing cells were imaged 48-72 hours after transfection. To detect the effect of salinomycin on receptor trafficking, salinomycin was added at $6 \mu \mathrm{M}$ concentration $3 \mathrm{~h}$ and $24 \mathrm{~h}$ before imaging.

For co-localization with lysosomes, $15 \mathrm{nM}$ lysotracker deep red was incubated for 1 hour on the cells, followed by medium exchange. To induce receptor endocytosis, $50 \mathrm{pmol} / \mathrm{ml} \mathrm{EGF}$ was added to the cells at 24 hours before measurement.

Spinning disk confocal microscopy was performed on a setup based on the TE200E microscope and the Yokogawa spinning disk unit CSU10. The system was equipped with a Nikon 1.49 NA 100x Plan Apo oil immersion objective.
For two color detection, cells were excited with alternating $488 \mathrm{~nm}$ and $641 \mathrm{~nm}$ laser light for $270 \mathrm{~ms}$ and $300 \mathrm{~ms}$ per frame. Fluorescence was split into two emission channels by a dichroic mirror (565, DCXR chroma) and passed through filter sets (525/50 and 730/140, semrock). Confocal z-stacks of cells were imaged with a spacing of $166 \mathrm{~nm}$ between two planes. Image sequences of both channels were captured on two EMCCD cameras (iXon; Andor). Images were geometrically calibrated according to reference images with Tetraspeck Beads. Overlay images and LUT images were built in ImageJ.

\section{Quantification}

To quantify the Fluo-3-AM and Lysotracker fluorescence in the cells, digital image analysis was performed in ImageJ: A threshold value for background fluorescence was set according to control images of untreated cells. The number and grey values of pixels above the set threshold was then determined for each image and the integrated intensity was calculated.

(integrated intensity $=$ number of selected pixels * mean grey value of selected pixels). Mean values of all evaluated cells are presented $(\mathrm{N}=8-10$ images for each incubation time).

For co-localization analysis the ImageJ macro $\mathrm{JaCOP}$ was applied. According to a manual threshold, the fluorescence signal in the red and green was selected. Next the fraction of green pixels overlapping red pixels was calculated (Manders coefficient, M1). Mean values of all evaluated cells ( $\mathrm{N}=7-13$ images) are presented together with the standard error of the mean (SEM).

\section{Molecular evolution assay}

This experiment was performed as described previously [39]. Briefly, MCF-7 cells were treated with $10 \mu \mathrm{M}$ tamoxifen or $0,05 \mu \mathrm{M}$ salinomycin for $72 \mathrm{~h}$ followed by a recovery phase until a confluence of $80 \%$. Afterwards, cells underwent five further treatment cycles and were harvested for subsequent experiments.

\section{Rhodamine efflux assay}

This assay was performed to measure the pump activity of expressed $\mathrm{ABC}$-transporter. Therefore, cells were trypsinized and diluted to an end concentration of $10^{6}$ cells $/ \mathrm{ml}$ with growth media.

Afterwards cells were treated with $0,2 \mu \mathrm{g} / \mathrm{ml}$ rhodamine for $30 \mathrm{~min}$, centrifuged and resuspended in $1 \mathrm{ml}$ media. Finally, the samples were analyzed by flow cytometry after the indicated time points.

\section{Mammosphere forming assay}

To figure out the cancer stem cell properties of cell populations, we utilized the mammosphere forming assay. 
For this test 10000 cells/well were seeded in ultra-low adherent plates (Corning) and cultivated in conditioned media for at 7 days. Afterwards spheroids were counted.

\section{Clonogenic assay}

To perform the clonogenic assay, $10^{3}$ cells were seeded in 6-well-plates (TPP; Switzerland), cultured for $24 \mathrm{~h}$ and subsequently treated for $72 \mathrm{~h}$ with tamoxifen, salinomycin and the combination.

Cells were then grown for 14 days, fixed and stained with paraformaldehyde (PFA) containing crystal violet. Surviving colonies were analyzed by ColonyArea, as previously described [40].

\section{ACKNOWLEDGMENTS}

The authors want to thank Mathias Falcenberg and Emanuele Zanucco for critically reading the manuscript. 3X ERE TATA luc was a gift from Donald McDonnell (Addgene plasmid \# 11354), Egfr-GFP was a gift from Alexander Sorkin (Addgene plasmid \# 32751) and perbB2-EGFP was a gift from Martin Offterdinger (Addgene plasmid \# 39321).

\section{CONFLICTS OF INTEREST}

The authors declare no conflict of interest.

\section{GRANT SUPPORT}

A.S. was supported by a doctoral fellowship from the Hanns-Seidel Stiftung, A.H. was supported by a doctoral fellowship from the Islamic Development Bank (28/IND/ P32). C.B. and E.W. acknowledge the financial support by the DFG Excellence Cluster Nanosystems Initiative Munich (NIM). This work was also supported by the German Research Foundation SFB1032/DFG (project B4).

\section{REFERENCES}

1. Society AC. (2016). Cancer Facts and Figures 2016. (Atlanta: American Cancer Society).

2. Society AC. (2015). Breast Cancer Facts and Figures 20152016. (Atlanta: American Cancer Society, Inc.).

3. Blows FM, Driver KE, Schmidt MK, Broeks A, van Leeuwen FE, Wesseling J, Cheang MC, Gelmon K, Nielsen TO, Blomqvist C, Heikkila P, Heikkinen T, Nevanlinna H, Akslen LA, Begin LR, Foulkes WD, et al. Subtyping of breast cancer by immunohistochemistry to investigate a relationship between subtype and short and long term survival: a collaborative analysis of data for 10,159 cases from 12 studies. PLoS medicine. 2010; 7:e1000279.

4. Eroles P, Bosch A, Perez-Fidalgo JA and Lluch A. Molecular biology in breast cancer: intrinsic subtypes and signaling pathways. Cancer treatment reviews. 2012; 38:698-707.

5. Johnston SR and Dowsett M. Aromatase inhibitors for breast cancer: lessons from the laboratory. Nature reviews Cancer. 2003; 3:821-831.

6. Demicheli R, Biganzoli E, Ardoino I, Boracchi P, Coradini D, Greco M, Moliterni A, Zambetti M, Valagussa P, Gukas ID and Bonadonna G. Recurrence and mortality dynamics for breast cancer patients undergoing mastectomy according to estrogen receptor status: different mortality but similar recurrence. Cancer science. 2010; 101:826-830.

7. Ring $A$ and Dowsett M. Mechanisms of tamoxifen resistance. Endocrine-related cancer. 2004; 11:643-658.

8. Garcia-Becerra R, Santos N, Diaz L and Camacho J. Mechanisms of Resistance to Endocrine Therapy in Breast Cancer: Focus on Signaling Pathways, miRNAs and Genetically Based Resistance. International journal of molecular sciences. 2012; 14:108-145.

9. Moerkens M, Zhang Y, Wester L, van de Water B and Meerman JH. Epidermal growth factor receptor signalling in human breast cancer cells operates parallel to estrogen receptor alpha signalling and results in tamoxifen insensitive proliferation. BMC cancer. 2014; 14:283.

10. Fuchs D, Daniel V, Sadeghi M, Opelz G and Naujokat C. Salinomycin overcomes ABC transporter-mediated multidrug and apoptosis resistance in human leukemia stem cell-like KG-1a cells. Biochemical and biophysical research communications. 2010; 394:1098-1104.

11. Gupta PB, Onder TT, Jiang G, Tao K, Kuperwasser C, Weinberg RA and Lander ES. Identification of selective inhibitors of cancer stem cells by high-throughput screening. Cell. 2009; 138:645-659.

12. Xiao Z, Sperl B, Ullrich A and Knyazev P. Metformin and salinomycin as the best combination for the eradication of NSCLC monolayer cells and their alveospheres (cancer stem cells) irrespective of EGFR, KRAS, EML4/ALK and LKB1 status. Oncotarget. 2014; 5:12877-12890. doi: 10.18632/oncotarget.2657.

13. Klose J, Stankov MV, Kleine M, Ramackers W, PanayotovaDimitrova D, Jager MD, Klempnauer J, Winkler M, Bektas $\mathrm{H}$, Behrens GM and Vondran FW. Inhibition of autophagic flux by salinomycin results in anti-cancer effect in hepatocellular carcinoma cells. PloS one. 2014; 9:e95970.

14. Jangamreddy JR, Ghavami S, Grabarek J, Kratz G, Wiechec E, Fredriksson BA, Rao Pariti RK, Cieslar-Pobuda A, Panigrahi $S$ and Los MJ. Salinomycin induces activation of autophagy, mitophagy and affects mitochondrial polarity: differences between primary and cancer cells. Biochimica et biophysica acta. 2013; 1833:2057-2069.

15. Jangamreddy JR, Panigrahi S and Los MJ. Monitoring of autophagy is complicated-salinomycin as an example. Biochimica et biophysica acta. 2014; 1853:604-610.

16. Jangamreddy JR, Jain MV, Hallbeck AL, Roberg K, Lotfi $\mathrm{K}$ and Los MJ. Glucose starvation-mediated inhibition 
of salinomycin induced autophagy amplifies cancer cell specific cell death. Oncotarget. 2015; 6:10134-10145. doi: 10.18632/oncotarget.3548.

17. Kopp F, Hermawan A, Oak PS, Herrmann A, Wagner E and Roidl A. Salinomycin treatment reduces metastatic tumor burden by hampering cancer cell migration. Molecular cancer. 2014; $13: 16$.

18. Kopp F, Hermawan A, Oak PS, Ulaganathan VK, Herrmann A, Elnikhely N, Thakur C, Xiao Z, Knyazev P, Ataseven B, Savai R, Wagner E and Roidl A. Sequential Salinomycin Treatment Results in Resistance Formation through Clonal Selection of Epithelial-Like Tumor Cells. Translational oncology. 2014; 7:702-711.

19. Schenk M, Aykut B, Teske C, Giese NA, Weitz J and Welsch T. Salinomycin inhibits growth of pancreatic cancer and cancer cell migration by disruption of actin stress fiber integrity. Cancer letters. 2015; 358:161-169.

20. Zhou Y, Liang C, Xue F, Chen W, Zhi X, Feng X, Bai X and Liang T. Salinomycin decreases doxorubicin resistance in hepatocellular carcinoma cells by inhibiting the beta-catenin/ TCF complex association via FOXO3a activation. Oncotarget. 2015; 6:10350-10365. doi: 10.18632/oncotarget.3585.

21. Zou ZZ, Nie PP, Li YW, Hou BX, Rui L, Shi XP, Ma ZK, Han BW and Luo XY. Synergistic induction of apoptosis by salinomycin and gefitinib through lysosomal and mitochondrial dependent pathway overcomes gefitinib resistance in colorectal cancer. Oncotarget. 2015; doi: 10.18632/oncotarget.5628.

22. Steel GG and Peckham MJ. Exploitable mechanisms in combined radiotherapy-chemotherapy: the concept of additivity. International journal of radiation oncology, biology, physics. 1979; 5:85-91.

23. Chou TC and Talalay P. Quantitative analysis of dose-effect relationships: the combined effects of multiple drugs or enzyme inhibitors. Advances in enzyme regulation. 1984; 22:27-55.

24. Chou TC. Drug combination studies and their synergy quantification using the Chou-Talalay method. Cancer research. 2010; 70:440-446.

25. Boehmerle W and Endres M. Salinomycin induces calpain and cytochrome c-mediated neuronal cell death. Cell death \& disease. 2011; 2:e168.

26. Lariccia V, Fine M, Magi S, Lin MJ, Yaradanakul A, Llaguno $\mathrm{MC}$ and Hilgemann DW. Massive calcium-activated endocytosis without involvement of classical endocytic proteins. The Journal of general physiology. 2011; 137:111-132.

27. Idone V, Tam C, Goss JW, Toomre D, Pypaert M and Andrews NW. Repair of injured plasma membrane by rapid $\mathrm{Ca} 2+-d e p e n d e n t$ endocytosis. The Journal of cell biology. 2008; 180:905-914.

28. Clarke R, Liu MC, Bouker KB, Gu Z, Lee RY, Zhu Y, Skaar TC, Gomez B, O'Brien K, Wang Y and HilakiviClarke LA. Antiestrogen resistance in breast cancer and the role of estrogen receptor signaling. Oncogene. 2003; 22:7316-7339.

29. Nicholson RI, Gee JM, Knowlden J, McClelland R, Madden TA, Barrow D and Hutcheson I. The biology of antihormone failure in breast cancer. Breast cancer research and treatment. 2003; 80 Suppl 1:S29-34; discussion S35.

30. Long B, McKibben BM, Lynch M and van den Berg HW. Changes in epidermal growth factor receptor expression and response to ligand associated with acquired tamoxifen resistance or oestrogen independence in the ZR-75-1 human breast cancer cell line. British journal of cancer. 1992; 65:865-869.

31. van Agthoven T, van Agthoven TL, Portengen H, Foekens JA and Dorssers LC. Ectopic expression of epidermal growth factor receptors induces hormone independence in ZR-75-1 human breast cancer cells. Cancer research. 1992; 52:5082-5088.

32. Miller DL, el-Ashry D, Cheville AL, Liu Y, McLeskey SW and Kern FG. Emergence of MCF-7 cells overexpressing a transfected epidermal growth factor receptor (EGFR) under estrogen-depleted conditions: evidence for a role of EGFR in breast cancer growth and progression. Cell growth \& differentiation. 1994; 5:1263-1274.

33. Liu Y, el-Ashry D, Chen D, Ding IY and Kern FG. MCF-7 breast cancer cells overexpressing transfected c-erbB-2 have an in vitro growth advantage in estrogendepleted conditions and reduced estrogen-dependence and tamoxifen-sensitivity in vivo. Breast cancer research and treatment. 1995; 34:97-117.

34. Chong K, Subramanian A, Sharma A and Mokbel K. Measuring IGF-1, ER-alpha and EGFR expression can predict tamoxifen-resistance in ER-positive breast cancer. Anticancer research. 2011; 31:23-32.

35. Hermawan A, Wagner E and Roidl A. Consecutive salinomycin treatment reduces doxorubicin resistance of breast tumor cells by diminishing drug efflux pump expression and activity. Oncology reports. 2016; 35:1732-1740.

36. Hall JM and McDonnell DP. The estrogen receptor betaisoform (ERbeta) of the human estrogen receptor modulates ERalpha transcriptional activity and is a key regulator of the cellular response to estrogens and antiestrogens. Endocrinology. 1999; 140:5566-5578.

37. Carter RE and Sorkin A. Endocytosis of functional epidermal growth factor receptor-green fluorescent protein chimera. The Journal of biological chemistry. 1998; 273:35000-35007.

38. Offterdinger $M$ and Bastiaens PI. Prolonged EGFR signaling by ERBB2-mediated sequestration at the plasma membrane. Traffic. 2008; 9:147-155.

39. Kopp F, Oak PS, Wagner E and Roidl A. miR-200c sensitizes breast cancer cells to doxorubicin treatment by decreasing TrkB and Bmil expression. PloS one. 2012; 7:e50469.

40. Guzman C, Bagga M, Kaur A, Westermarck J and Abankwa D. ColonyArea: an ImageJ plugin to automatically quantify colony formation in clonogenic assays. PloS one. 2014; 9:e92444. 